\title{
Effects of Art Therapy Program on Anxiety and Depression among 6-12-Year-Old Burned Children
}

\author{
Hossein Rezazadeh ${ }^{1}$, Razieh Froutan ${ }^{2,3}$, Ali Ahmad Abadi ${ }^{4}$, Seyed Reza Mazloum ${ }^{2,3}$, Kaveh Moghaddam ${ }^{5}$ \\ ${ }^{1}$ Critical Care Nursing, School of Nursing and Midwifery, Mashhad University of Medical Sciences, Mashhad, Iran; ${ }^{2}$ Department \\ of Medical Surgical Nursing, School of Nursing and Midwifery, Mashhad University of Medical Sciences, Mashhad, Iran; \\ ${ }^{3}$ Nursing and Midwifery Care Research Center, Mashhad University of Medical Sciences, Mashhad, Iran; ${ }^{4}$ Surgical Oncology \\ Research Center, Mashhad University of Medical Sciences, Mashhad, Iran; ${ }^{5}$ Exceptional children Psychology and Education, \\ University of Social Sciences and Researches, Tehran, Iran
}

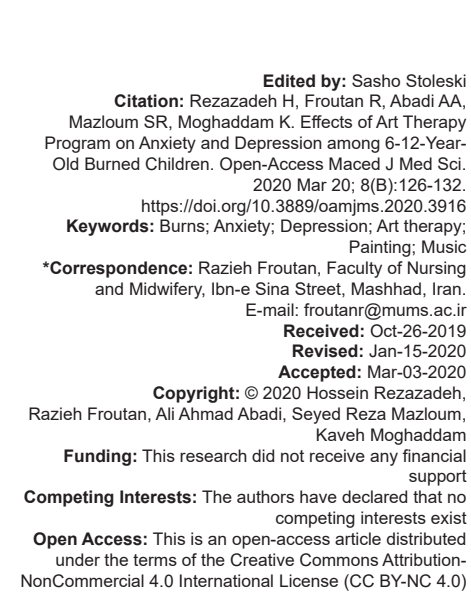

\section{Introduction}

Burns are among the most important human health-related accidents due to the high morbidity and mortality rates [1]. The death toll in the United States is $1.2 / 100,000$ population, compared to 3.8 in Iran in recent years [2]. Burning is the fourth injury type after collisions, falling from heights, and arguments. Moreover, it is the second leading cause of death after road accidents [3]. Post-traumatic stress disorder usually occurs in $30 \%$ of children who are severely burned [4], [5], [6].

Psychiatric examination of the survivors of burn injuries indicates that they suffer from psychological disorders, such as anxiety, depression, and posttraumatic stress disorder, due to the toleration of painful therapeutic methods and disruption of social roles. Pain induces anxiety and stress, thereby causing exacerbation of pain [7]. Physical and psychological consequences of pain are common complications among burned patients that ultimately lead to permanent physical and mental changes in the patient [8], [9]. There is a strong relationship between the severity of burns and subsequent mental disorders [10].

In Iran, children account for more than half of the cases with severe burns (40-50\%) [10], [11] [12], [13]. The treatment of children with burns is very challenging, as burn injuries are among the most severe traumas they may experience [14]. Hospitalized children with burns may experience severe pain, stress, and posttraumatic stress disorder syndrome as a result of painful medical procedures, such as skin grafts, debridement, and rehabilitation therapies [15], [16], [17]. Some children may suffer from long-term psychosocial problems, such as depression and social dysfunction, which requires attention and interference. Moreover, there is evidence regarding behavioral problems, lower self-esteem, or distorted mental image in children after burns [18]. 
Another common problem in children with burns is anxiety. Hospitalized children are confronting with anxiety and negative feelings concerning serious health problems and unfamiliar hospital environments [19]. Children who experience a great deal of stress in their pre-treatment period develop posttreatment regressions, such as delirium, nocturia, and nightmare [20]. Depression is another psychological complication reported after burns. The frequency of symptoms of depression in the $1^{\text {st }}$ year after injury varies widely and depends on the applied measures [21].

One of the strategies suggested to reduce depression and anxiety in these patients is the usage of non-pharmacological methods (i.e., art therapy). Art therapy employs creative ways of creating art to enhance the physical, mental, and emotional health of all ages [22].

Art therapy means using various artistic instruments through which patients can express themselves and deal with the issues and concerns that have brought them into the therapeutic environment. This method is an intervention that can be used to improve psychological abnormalities, as well as reducing cognitive, emotional, behavioral, and communication problems from childhood to adulthood in clinical centers, institutions, and clinics [21]. The first art therapy instrument is painting that can be used for different age groups [23].

Painting therapy is a valuable communication instrument for children who cannot openly express their feelings for different reasons, such as fear and humiliation. During the painting, children can draw their thoughts, show dissatisfaction from their surroundings and hospital, and express their true feelings in a safe environment. In other words, painting improves anger management abilities, helps to find corrective/adaptive responses, and develops problem-solving skills in children. Moreover, it allows to find a non-invasive way to communicate in an environment that is emotionally complex [24], [25]. The painting was shown to be used as a language to evoke emotions, such as aggression, because children have more limited vocabulary to express their emotional experiences than adults [26].

The results of another study on children with cancer showed that art therapy (e.g., painting and pottery) is an effective method for patients to express feelings about their illness. As a result, art therapy can help the recovery process by reducing anxiety and depression. Engagement in artworks can accelerate the completion of the recovery process of the patients. In addition, the results of a study conducted by Russell to assess the effect of art therapy on the recovery and rehabilitation of the burns patients in the US demonstrated the effectiveness of art therapy in these patients [27].

Another branch of art therapy is music therapy, which has been studied by many researchers around the world. Music is used to treat many physical, emotional, and psychological problems in different people, the most notable of which include pain, anxiety, sadness, and communication problems [28].

Music is used for the evacuation of emotions, relaxation, and confrontation with conflicts, awareness, insight improvement, and adaptation. The brain structure is such that responds positively to musical stimuli, thereby facilitating the use of this therapy [29]. Therefore, the American Music Therapy Association (AMTA) considers music therapy as a method based on clinical utility and experience. The AMTA believes that the purpose of music therapy is to form a therapeutic relationship and empower physical and mental health [30].

In nursing practice, music as an effective intervention can be part of the patient care plan and be used as a non-invasive therapy to relieve pain and anxiety [31]. Different studies showed that music therapy could have positive impacts on patients with cancer and asthma [32], [33].

Currently, in Iranian hospitals, especially in burn centers, art therapy is not used to relieve pain, anxiety, and depression in patients. To the best of our knowledge, there has been no study in Iran investigating the impacts of art therapy on reducing anxiety and depression in burned children.

On the other hand, for reasons, such as cultural and social differences, the results of overseas studies cannot be fully extended to patients within our country. Therefore, there is a necessity to conduct further research at the national level. The recommendation and use of non-pharmacological approaches are defined in the nursing domain [31]. Despite the advantages of art therapy, such as cost-effectiveness and easy access, there are no similar studies addressing the impact of art therapy among burned children. With this background in mind, the present study was conducted to investigate the impacts of art therapy on reducing anxiety and depression among burned children.

\section{Materials and Methods}

This three-group randomized clinical trial was performed at Mashhad University of Medical Sciences, Mashhad, Iran. This study was approved by the Ethics Committee under the number of IR.MUMS. REC.1397.103 and registered with the code number of IRRC20180618040142N1 at the Iran Clinical Trial Center. After receiving the letter, it was submitted to the authorities in charge of the research setting, and the necessary coordination was performed. The present study was performed on patients suffering from burns who were admitted to the Burn Center of Imam Reza Hospital, Mashhad, Iran. To randomize the study population by SPSS software before entering the data, individuals were divided into two groups. 
After the introduction, the researcher selected subjects who met the eligibility criteria. The inclusion criteria were: (1) Alertness, (2) burn diagnosis leading to admission to the Burn Center of Imam Reza Hospital, (3) lack of cognitive or mental disorders based on medical records, (4) lack of hearing or visual impairments and hand disabilities, (5) age of $<12$ and $>6$ years, (6) a phone number to call after discharge, (7) no burns in the dominant hand, and (8) no ear, face, or head burns.

The exclusion criteria of the present study were: (1) Reluctance of patient family to continue the art therapy program at any stage of the study, (2) exacerbation of the patient illness and special care need, (3) no response to telephone follow-ups after discharge, and (4) emergence of audiovisual problems during the research. After one by one provision of the oral explanations about the purpose and method of the research, written informed consent was obtained from the selected individuals.

The parent version of the Spence Children's Anxiety Scale (SCAS-P) was used to measure anxiety. This 28-item questionnaire consists of five domains measuring children's anxiety based on a five-point Likert scale. This tool has a score range of 0-112 [34]. Maria Kovacs Children's Depression Inventory was used to measure depression in children. This is a 27-item questionnaire used to assess depression symptoms in children.

The items of this questionnaire were taken from the Beck Depression Inventory. This instrument can facilitate the detection of any symptoms that are specific to childhood depression. The questionnaire consists of five scales, including negative mood, interpersonal problems, feelings of inadequacy, lack of pleasure, and low self-esteem. Items are scored on a scale from 0 (no symptom) to 2 (no specific symptoms). This tool has a score range of 0-54 with a higher score indicating severe depression [35]. The questionnaires were completed by the researcher before and after the art therapy sessions.

Qualitative content validity was used to determine the validity of the questionnaires (participant selection, demographic form, and informed consent form). To this end, the questionnaire was evaluated by ten professors and experts (e.g., supervisor, expert advisors, and faculty members of Mashhad School of Nursing and Midwifery, Mashhad, Iran), and the necessary corrections were made. On the other hand, since the demographic form and informed consent form contained clear questions were repeatedly used and validated in different studies, they did not need to be tested for reliability.

The reliability of the SCAS was confirmed in a previous study, rendering a Cronbach's alpha coefficient of $>0.7$ [36]. Previous studies have also shown good psychometric properties for the Maria Kovacs Children's Depression Inventory Questionnaire [37].

The sample size was estimated based on a pilot study on ten subjects in each group using a comparison of means formula for both anxiety and depression indices. Ultimately, the largest number was considered as the sample size of this study. The final sample size was calculated at 18 individuals in each group, according to the confidence level of $95 \%$ and test power of $80 \%$. However, more than 20 individuals in each group (60 in total) were entered into the study, and all of them completed the research.

In addition to the usual treatments, the intervention group painted for 10 days during 45-min individual sessions, along with their legal guardian. The meetings were held in the evening shifts after the meeting hours ended in the playroom of the burn center. Pencils and markers were used for drawing for $15 \mathrm{~min}$ after which the researcher talked to the children for about $30 \mathrm{~min}$. Conversations were revolved around painting to help the patient express his possible concerns more easily. The program was conducted by a researcher (after receiving the necessary training) and under the supervision of an art therapist in the hospital burn center.

In the music group, an instrumental music provided by a child art therapist was used identically for all children. It was played through a speaker with the same intensity and decibel for 15 min continuously for each child, and the child was accompanied by a guardian and the researcher. After listening to the music, the researcher spoke with the child about his feelings about the music being played about $30 \mathrm{~min}$. These programs were performed by the researcher (who had received the necessary training) under the supervision of an art therapist in the burn center of the hospital. The control group only received routine treatments.

In line with research ethics principles, confidentiality terms were taken into account, and informed consent was obtained from all patients. The data were analyzed using SPSS software (version 21). Accordingly, Kolmogorov-Smirnov and Shapiro-Wilk tests were used to determine the normality of data.

To investigate the homogeneity of the two groups and research objectives, Chi-square test and one-way ANOVA were performed for qualitative and quantitative variables with normal distribution, respectively. In addition, Kruskal-Wallis test was adopted for quantitative variables without normal distribution. The intragroup comparisons were performed using the Wilcoxon test (for variables without normal distribution) and paired t-test (for variables with normal distribution). In all the used tests, the confidence level of $95 \%$ and significance level of 0.05 were considered.

\section{Results}

A total of 60 patients were enrolled in the current study. The data were analyzed for patients in 
the two intervention groups $(n=40)$ and control group $(n=20)$. Of the studied subjects, $12(60 \%), 9(45 \%)$, and $11(55 \%)$ cases in the painting, music, and control groups were male, respectively. Chi-square test showed no significant difference among the three groups in terms of genders $(p=0.626)$.

The mean ages of the painting, music, and control groups were $9.9 \pm 1.4,10.1 \pm 1.4$, and $9.6 \pm$ 1.2 years, respectively. The results of Kruskal-Wallis test showed no significant difference among the three groups regarding age $(p=0.515)$.

Children in the three groups were homogeneous concerning such variables as alive parents $(p=0.122)$, number of family members ( $p=0.558)$, number of brothers $(p=0.241)$, number of sisters $(p=0.927)$, birth rate $(p=0.800)$, number of used medication $(p=0.849)$, gender $(p=0.626)$, chronic disease $(p=0.100)$, and educational level $(p=0.100$; Table 1$)$.

Table 1: Comparison of the three research groups in terms of demographic data

\begin{tabular}{|c|c|c|c|c|}
\hline Group variable & $\begin{array}{l}\text { Painting } \\
(\mathrm{n}=20)\end{array}$ & $\begin{array}{l}\text { Music } \\
(n=20)\end{array}$ & $\begin{array}{l}\text { Control } \\
(n=20)\end{array}$ & Test/p-value \\
\hline Age (year) Mean $\pm S D$ & $9.9 \pm 1.4$ & $10.1 \pm 1.4$ & $9.6 \pm 1.2$ & Kruskal-Wallis $/ \mathrm{p}=0.515$ \\
\hline $\begin{array}{l}\text { Number of family } \\
\text { members Mean } \pm S D\end{array}$ & $5.5 \pm 1.9$ & $5.5 \pm 1.7$ & $4.9 \pm 1.3$ & Kruskal-Wallis $/ p=0.581$ \\
\hline Birth rate Mean $\pm S D$ & $2.7 \pm 1.7$ & $2.3 \pm 1.0$ & $2.2 \pm 1.2$ & Kruskal-Wallis $/ \mathrm{p}=0.800$ \\
\hline \multicolumn{5}{|l|}{ Gender n (\%) } \\
\hline Boy & $12(60.0)$ & $9(45.0)$ & $11(55.0)$ & Chi-square/p=0.626 \\
\hline Girl & $8(40.0)$ & $11(55.0)$ & $9(45.0)$ & \\
\hline \multicolumn{5}{|l|}{ Alive parent } \\
\hline Yes & $20(100.0)$ & $16(80.0)$ & $19(95.0)$ & Exact Chi-square $/ p=0.112$ \\
\hline No & $0(0.0)$ & $4(20.0)$ & $1(5.0)$ & \\
\hline \multicolumn{5}{|l|}{ Chronic illness } \\
\hline Yes & $2(10.0)$ & $2(10.0)$ & $2(10.0)$ & Exact Chi-square $/ p=0.100$ \\
\hline No & $18(90.0)$ & $18(90.0)$ & $18(90.0)$ & \\
\hline
\end{tabular}

In the pre-intervention phase, the total mean scores of anxiety in the painting, music, and control groups were measured at $90.4 \pm 5.4,84.8 \pm 6.8$, and $77.4 \pm 13.8$ years, respectively. The Kruskal-Wallis test showed a significant difference among the three groups in terms of anxiety score $(p<0.001)$. Dunn's post hoc test demonstrated a significant difference between the painting and music groups $(p=0.014)$ and between the painting and control groups in this regard $(p<0.001)$. However, the difference between the music and control groups was not statistically significant $(p=0.158)$.

In the post-intervention phase, the total mean scores of anxiety were measured at $4.4 \pm 53.3,45.9 \pm$ 8.4 , and $72.4 \pm 12.9$ in the painting, music, and control groups, respectively. The Kruskal-Wallis test showed a significant difference among the groups regarding this variable $(p<0.001)$. According to the Dunn's post hoc test, there was a significant difference in this regard between the two groups of painting and music, painting and control, and music and control, respectively ( $p=0.008, p<0.001, p<0.001)$.

Since the pre-intervention anxiety was not comparable among the groups, covariance analysis was used to eliminate the effect of this variable. The results revealed a significant difference in anxiety scores after the intervention between the two groups, even after eliminating the pre-intervention anxiety $(p<0.001)$.
The differences in the post-intervention anxiety score, compared to the pre-intervention anxiety score, were obtained as $-37.1 \pm 5.9,-39.0 \pm 8.4$, and $0.5 \pm 4.4$ in the painting, music, and control groups, respectively (negative number means reduction). The results of oneway ANOVA were indicative of a significant difference among the groups in this regard $(p<0.001)$. The results of Tukey post hoc test also showed a significant difference between the two groups of painting and control $(p<0.001)$ and music and control $(p<0.001)$. However, the difference between the painting and music groups was not significant $(p=0.622)$.

An intra-group comparison by the paired t-test and Wilcoxon test showed a significant difference in the anxiety score in the painting ( $p<0.001)$, music ( $p<0.001)$, and control groups $(p=0.001)$ after the intervention, compared to those obtained before the intervention (Table 2).

Table 2: Total anxiety mean score in the three groups at the pre- and post-intervention stages

\begin{tabular}{|c|c|c|c|c|}
\hline \multirow{3}{*}{$\begin{array}{l}\text { Total anxiety } \\
\text { score }\end{array}$} & \multicolumn{3}{|l|}{ Group } & \multirow{3}{*}{$\begin{array}{l}\text { Test result } \\
\text { (Intra-group) }\end{array}$} \\
\hline & $\begin{array}{l}\text { Painting } \\
(n=20)\end{array}$ & $\begin{array}{l}\text { Music } \\
(n=20)\end{array}$ & $\begin{array}{l}\text { Control } \\
(n=20)\end{array}$ & \\
\hline & Mean $\pm S D$ & Mean $\pm S D$ & Mean \pm SD & \\
\hline Before & $90.4 \pm 5.4$ & $84.8 \pm 6.8$ & $77.4 \pm$ & $p>0.001$ \\
\hline intervention & & & 13.8 & Kruskal-Wallis \\
\hline $\begin{array}{l}\text { After } \\
\text { intervention }\end{array}$ & $53.3 \pm 4.4$ & $45.9 \pm 8.4$ & $\begin{array}{l}72.4 \pm \\
12.9\end{array}$ & $\begin{array}{l}p>0.001 \\
\text { Kruskal-Wallis }\end{array}$ \\
\hline $\begin{array}{l}\text { Mean difference } \\
\text { after intervention }\end{array}$ & $-37.1 \pm 5.9$ & $-39.0 \pm 8.4$ & $-5.0 \pm 4.4$ & $\begin{array}{l}p>0.001 \\
\text { One-way ANOVA }\end{array}$ \\
\hline $\begin{array}{l}\text { Intra-group test } \\
\text { result }\end{array}$ & $\begin{array}{l}p>0.001 \\
\text { Paired t-test }\end{array}$ & $\begin{array}{l}p>0.001 \\
\text { Paired t-test }\end{array}$ & $\begin{array}{l}p>0.001 \\
\text { Wilcoxon }\end{array}$ & \\
\hline
\end{tabular}

In the pre-intervention phase, the mean scores of depression in the painting, music, and control groups were measured at $38.7 \pm 3.4,32.8 \pm 5.4$, and $28.9 \pm$ 5.4 , respectively. Moreover, one-way ANOVA showed a significant difference among the groups in terms of this variable $(p<0.001)$. Tukey's post hoc test showed a significant difference between the two groups of painting and music, painting and control, and music and control ( $p=0.001, p<0.001$, and $p=0.038$, respectively).

After the intervention, the total mean score of depression was estimated at $29.9 \pm 4.0,19.3 \pm 3.8$, and $25.2 \pm 4.9$ in the painting, music, and control groups, respectively. One-way ANOVA demonstrated this difference to be significant ( $p<0.001)$. The results of the Tukey's post hoc test showed a significant difference between the two groups of painting and music, painting and control, and music and control $(p<0.001, p=0.003$, and $p<0.001$, respectively).

Regarding the non-homogeneity of the total depression score before the intervention, the covariance analysis test was used to eliminate its effect $(p<0.001)$. After eliminating the effect of depression score before the intervention, there was still a significant difference between the two groups considering the depression score $(p<0.001)$.

The mean differences of depression total score after the intervention were measured at $-8.8 \pm$ $4.1,-13.5 \pm 3.8$, and $-3.7 \pm 2.5$ in the painting, music, and control groups, respectively (negative means 
reduction). In addition, one-way ANOVA showed a significant difference among the groups concerning this variable $(p<0.001)$. In this regard, Tukey's post hoc test revealed a significant difference between the two groups of painting and music ( $p<0.001)$, painting and control ( $p<0.001)$, and control groups $(p<0.000)$.

In-group comparison by paired t-test showed a significant difference in the depression scores obtained at the post-intervention stage, compared to the preintervention scores in the painting, music, and control groups $(p<0.001, p<0.001, p=0.001$; Table 3$)$.

Table 3: Total mean score of depression in the study groups

\begin{tabular}{|c|c|c|c|c|}
\hline \multirow{2}{*}{$\begin{array}{l}\text { The total } \\
\text { depression score }\end{array}$} & \multicolumn{3}{|l|}{ Group } & \multirow{2}{*}{$\begin{array}{l}\text { Test result } \\
\text { (Intra-group) }\end{array}$} \\
\hline & $\begin{array}{l}\begin{array}{l}\text { Painting } \\
(n=20)\end{array} \\
\text { Mean } \pm S D\end{array}$ & $\begin{array}{l}\begin{array}{l}\text { Music } \\
(n=20)\end{array} \\
\text { Mean } \pm S D\end{array}$ & $\begin{array}{l}\text { Control } \\
(n=20)\end{array}$ & \\
\hline Before & $38.7 \pm 3.4$ & $32.8 \pm 5.4$ & $28.9 \pm 5.4$ & $p>0.001$ \\
\hline $\begin{array}{l}\text { intervention } \\
\text { After intervention }\end{array}$ & $29.9 \pm 4.0$ & $19.3 \pm 3.8$ & $25.2 \pm 4.9$ & $\begin{array}{l}\text { One-way ANOVA } \\
p>0.001\end{array}$ \\
\hline $\begin{array}{l}\text { Mean difference } \\
\text { after intervention }\end{array}$ & $-8.8 \pm 4.1$ & $-13.5 \pm 3.8$ & $-3.7 \pm 2.5$ & $\begin{array}{l}\text { One-way ANOVA } \\
p>0.001 \\
\text { One-way ANOVA }\end{array}$ \\
\hline $\begin{array}{l}\text { Intra-group test } \\
\text { result }\end{array}$ & $\begin{array}{l}p>0.001 \\
\text { Paired t-test }\end{array}$ & $\begin{array}{l}p>0.001 \\
\text { Paired t-test }\end{array}$ & $\begin{array}{l}p>0.001 \\
\text { Paired t-test }\end{array}$ & \\
\hline
\end{tabular}

\section{Discussion}

The present three-group randomized clinical trial involved the investigation of 60 hospitalized burned children aged 6-12 years divided into two intervention groups (i.e., painting and music) and one control group to evaluate the impact of art therapy on anxiety and depression. The results revealed a significant decrease in the mean anxiety score in the intervention group, compared to that in the control group after the implementation of painting and music-based art therapy.

Many studies have investigated the effects of different art therapy methods on promoting children's health. Khodabakhshi et al., investigating the effects of using painting on anxiety levels in children hospitalized due to cancer, reported a decrease in the mean anxiety from 60.90 to 40.90 after the implementation of the painting program [38]. In another study, Shirabadi and Jani (2015) examined the effectiveness of painting-based art therapy in reducing anxiety in stuttering children. The results of the mentioned study showed that paintingbased art therapy was effective in mitigating anxiety in these children [39]. In the same vein, the results of another study were suggestive of the effectiveness of paining-based art therapy in the reduction of anxiety levels in children suffering from asthma [40]. The positive effects of therapeutic painting were confirmed in other studies, too [41], [42]. The positive effects of playing music on reducing children's anxiety have also been addressed in a study by Li et al. They reported a positive correlation between different therapies, such as music therapy interventions and anxiety mitigation, heart rate reduction, and pain relief in burned patients [14].
These findings are consistent with the results of the present study. In the current study, there was a significant difference between the control and music groups in terms of anxiety level after the intervention; in this regard, the anxiety of the children decreased following the implementation of music therapy. The results of our study are also consistent with the findings of Rabiee et al., who examined the effect of music on anxiety among hospitalized children [43].

These results are probably due to the effectiveness of hearing stimulation in relieving pain. For this reason, music can be used as a pain control strategy. However, conflicting results have also been reported in previous studies. For instance, the results of the Whitehead-Pleaux et al. (2006) showed that the effects of music interventions were not significant in relieving pain and anxiety in children undergoing donor dressing change [44].

Other findings of the present study indicated that after the painting and music interventions, the depression means score in the intervention group was significantly reduced compared to that in the control group. Furthermore, the results of other studies showed that music and painting can both reduce depression. Therefore, it seems that along with existing therapeutic protocols, the simultaneous use of nonpharmacological interventions (e.g., painting and music) can improve depression more effectively [45]. For instance, a study addressed the impact of 10 sessions of painting-based art therapy on reducing depression, anxiety, and aggression in 30 pre-school children with psychological problems. The findings of the mentioned study showed the effect of paintingbased art therapy on mitigating the aforementioned states in preschool children [46]. Therefore, regarding the diminishing effects of depression, anxiety, and aggression in such children, greater attention should be paid to the role of art therapy as one of the treatment strategies for disorders in children. Many studies have investigated the impact of music therapy on depression. For instance, Tahan et al. examined the effectiveness of music therapy on depression, stress, and anxiety in Vali-e-Asr Hospital, Birjand, Iran, within 2017. The study population of the mentioned study included 40 individuals who were randomly divided into two groups of case and control. The data collection instrument was the depression, anxiety, and stress scale. The intervention group received music therapy for 6 days. The findings indicated that depression and anxiety in the case group were significantly lower than those in the control group [47]. In a study conducted by Jasemi et al., it was found that music therapy significantly reduced depression and anxiety, which is in line with the results of the current study [48]. Children with burns often have impulse control problems. Elevated impulsivity is an important issue in dealing with these children. Regarding this, it is fundamental issue to adopt a treatment that can primarily facilitate the 
establishment of communication in these children and encourage them to undergo medical interventions and treatments, thereby effectively helping these children in dealing with their problems.

\section{Conclusion}

According to the findings of the present study, it can be concluded that painting and music therapies can enhance impulse control and decrease impulsivity in these children. Since music is the most important way to get into the world of children, it can help us to understand both children's problems and to some extent eliminate the problems resulting from the lack of impulse control.

\section{Acknowledgment}

The present study was derived from a thesis in master of nursing, Mashhad University of Medical Sciences, School of Nursing and Midwifery. We are grateful to Research deputy of Mashhad University of Medical Sciences for great cooperation on this research. Also we would like to thank all of our small patients and their families and also nurses who helped us in this study.

\section{References}

1. World Health Organization. Burn Prevention: Success Stories and Lessons Learned. Geneva: World Health Organization; 2011.

2. Peck MD. Epidemiology of burns throughout the world. Part I: Distribution and risk factors. Burns. 2011;37(7):1087-100. https://doi.org/10.1016/j.burns.2011.06.005 PMid:21802856

3. Mohebbi Z, Najafi S, Molazem Z, Setoodeh G. Epidemiology, causes and outcome of burns in women from Southern Iran: 2009-2011. Womens Health Bull. 2014;1(2):e20123. https://doi. org/10.17795/whb-20123

4. Kudchadkar SR, Aljohani OA, Punjabi NM. Sleep of critically ill children in the pediatric intensive care unit: A systematic review. Sleep Med Rev. 2014;18(2):103-10. https://doi.org/10.1016/j. smrv.2013.02.002

PMid:23702219

5. Norambuena C, Yañez J, Flores V, Puentes $P$, Carrasco $P$, Villena R. Oral ketamine and midazolam for pediatric burn patients: A prospective, randomized, double-blind study. J Pediatr Surg. 2013;48(3):629-34. https://doi.org/10.1016/j. jpedsurg.2012.08.018

PMid:23480923
6. Saxe GN, Stoddard F, Hall E, Chawla N, Lopez C, Sheridan R, et al. Pathways to PTSD, part I: Children with burns. Am J Psychiatry. 2005;162(7):1299-304. https://doi.org/10.1176/appi. ajp.162.7.1299

PMid:15994712

7. Tan X, Yowler CJ, Super DM, Fratianne RB. The efficacy of music therapy protocols for decreasing pain, anxiety, and muscle tension levels during burn dressing changes: A prospective randomized crossover trial. J Burn Care Res. 2010;31(4):590-7. https://doi.org/10.1097/bcr.0b013e3181e4d71b PMid:20498613

8. Branson SM, Boss L, Padhye NS, Trötscher T, Ward A Effects of animal-assisted activities on biobehavioral stress responses in hospitalized children: A randomized controlled study. J Pediatr Nurs. 2017;36:84-91. https://doi.org/10.1016/j. pedn.2017.05.006

PMid:28888516

9. Herndon D. Total Burn Care. $2^{\text {nd }}$ ed. Londen: Saunders; 2012.

10. Palmu R, Suominen K, Vuola J, Isometsä E. Mental disorders after burn injury: A prospective study. Burns. 2011;37(4):601-9. https://doi.org/10.1016/j.burns.2010.06.007 PMid:21081260

11. Alaghehbandan R, Lari AR, Joghataei MT, Islami A. The role of marital status, literacy, and urbanity in suicidal behavior by burns in the province of Khorasan, Iran. Community Ment Health J. 2011;47(2):181-5. https://doi.org/10.1007/s10597-010-9297-1 PMid:20130990

12. Arshi $\mathrm{S}$, Sadeghi-Bazargani $\mathrm{H}$, Mohammadi $\mathrm{R}$, Ekman $\mathrm{R}$, Hudson D, Djafarzadeh $\mathrm{H}$, et al. Prevention oriented epidemiologic study of accidental burns in rural areas of Ardabil, Iran. Burns. 2006;32(3):366-71. https://doi.org/10.1016/j.burns.2005.10.026 PMid: 16529866

13. Mirmohammadi SJ, Mehrparvar AH, Kazemeini $\mathrm{K}$ Mostaghaci M. Epidemiologic characteristics of occupational burns in Yazd, Iran. Int J Prev Med. 2013;4(6):723-7. PMid:23930193

14. Li J, Zhou L, Wang Y. The effects of music intervention on burn patients during treatment procedures: A systematic review and meta-analysis of randomized controlled trials. BMC Complement Altern Med. 2017;17(1):158. https://doi. org/10.1186/s12906-017-1669-4 PMid:28302117

15. De Young AC, Kenardy JA, Cobham VE, Kimble R. Prevalence, comorbidity and course of trauma reactions in young burninjured children. J Child Psychol Psychiatry. 2012;53(1):56-63. https://doi.org/10.1111/j.1469-7610.2011.02431.x

PMid:21671940

16. Richardson $P$, Mustard $L$. The management of pain in the burns unit. Burns. 2009;35(7):921-36. https://doi.org/10.1016/j. burns.2009.03.003

PMid: 19505764

17. Stoddard FJ, Saxe G, Ronfeldt H, Drake JE, Burns J, Edgren C et al. Acute stress symptoms in young children with burns. J Am Acad Child Adolesc Psychiatry. 2006;45(1):87-93. https://doi. org/10.1097/01.chi.0000184934.71917.3a PMid: 16327585

18. Holaday M, Terrell D. Resiliency characteristics and Rorschach variables in children and adolescents with severe burns. J Burn Care Rehabil. 1994;15(5):455-60. https://doi. org/10.1097/00004630-199409000-00017 PMid:7995822

19. Goldschmidt K, Woolley A. Using technology to reduce childrens anxiety throughout the perioperative period. J Pediatr Nurs. 2017;36:256-8. https://doi.org/10.1016/j.pedn.2017.04.006 


\section{PMid:28457695}

20. Wiechman S, Saxe G, Fauerbach JA. Psychological outcomes following burn injuries. J Burn Care Res. 2017;38(3):e629-31. https://doi.org/10.1097/bcr.0000000000000549 PMid:28346301

21. Case C, Dalley T. The Handbook of Art Therapy. Abingdon, United Kingdom: Routledge; 2014.

22. Nissimov-Nahum E. Use of a drawing task to study art therapists' personal experiences in treating aggressive children. Arts Psychother. 2009;36(3):140-7. https://doi.org/10.1016/j. aip.2008.12.001

23. Rubin JA. Child Art Therapy. New Jersey, United States: John Wiley \& Sons; 2005.

24. Liebmann M. Art Therapy and Anger. London, United Kingdom: Jessica Kingsley Publishers; 2008.

25. Waller D. Group Interactive Art Therapy: Its Use in Training and Treatment. Abingdon, United Kingdom: Routledge; 2014.

26. Hamel NJ. Children's Understanding and Experience of Anger within their Peer Groups. Ontario: The University of Western Ontario; 2013.

27. Russell J. Art therapy on a hospital burn unit: A step towards healing and recovery. Art Therapy. 1995;12(1):39-45. https://doi. org/10.1080/07421656.1995.10759122

28. Keihani M, Shariatpanahi M. The effect of music on concentration and attention among students of Tehran University of medical sciences. Islam Azad Univ J Med Sci. 2008;18(2):101-6.

29. Kousha S, Varasteh A. The effectiveness of music therapy on depression, quality of life and happiness of women with depression. Frooyesh. 2018;6(4):149-70.

30. Liu Y, Petrini MA. Effects of music therapy on pain, anxiety, and vital signs in patients after thoracic surgery. Complement Ther Med. 2015;23(5):714-8. https://doi.org/10.1016/j.ctim.2015.08.002 PMid:26365452

31. McCaffrey R, Locsin RC. Music listening as a nursing intervention: A symphony of practice. Holist Nurs Pract. 2002;16(3):70-7. https://doi.org/10.1097/00004650-200204000-00012 PMid:11913230

32. Burns DS, Perkins SM, TongY, Hilliard RE, Cripe LD. Musictherapy is associated with family perception of more spiritual support and decreased breathing problems in cancer patients receiving hospice care. J Pain Symptom Manage. 2015;50(2):225-31. https://doi.org/10.1016/j.jpainsymman.2015.02.022 PMid:25839735

33. Fredenburg HA, Silverman MJ. Effects of cognitive-behavioral music therapy on fatigue in patients in a blood and marrow transplantation unit: A mixed-method pilot study. Arts Psychother. 2014;41(5):433-44. https://doi.org/10.1016/j.aip.2014.09.002

34. Spence $\mathrm{SH}$, Rapee $\mathrm{R}$, McDonald $\mathrm{C}$, Ingram $\mathrm{M}$. The structure of anxiety symptoms among preschoolers. Behav Res Ther. 2001;39(11):1293-316. https://doi.org/10.1016/ s0005-7967(00)00098-x

PMid: 11686265

35. Kovacs M. The children's depression, inventory (CDI) Psychopharmacol Bull. 1985;21(4):995-8.

PMid:4089116

36. Ghanbari S, Khanmohamadi M, Khodapanahi MK, Mazaheri MA, Lavasani MG. Study of psychometric properties of preschool anxiety scale (PAS). J Psychol. 2011;3(59):222-34

37. Mirzaie P, Nazarian L, Zare H. Validation of the Maria Kovacs Children's depression inventory to assess depression among school children in Afghanistan. J Midwifery Reprod Health. 2019;7(3):1742-8.

38. Koolaee AK, Vazifehdar R, Bahari F. Impact of painting therapy on aggression and anxiety of children with cancer. Caspian $J$ Pediatr. 2016;2(2):135-41.

39. Shirabadi A, Jani S, Pouresmali A. Effectiveness of art therapy based on painting therapy to reduce anxiety of children with stuttering. Sci J Ilam Univ Med Sci. 2015;23(2):53-60.

40. Beebe A, Gelfand EW, Bender B. A randomized trial to test the effectiveness of art therapy for children with asthma J Allergy Clin Immunol. 2010;126(2):263-6, 266.e1. https://doi. org/10.1016/j.jaci.2010.03.019

PMid:20462632

41. Moghaddam HE, Badrizadeh A, Farhadi A. Study of anxiety symptoms in drawing-a-person test of Khorramabad 10 years old children. Yafteh. 2014;15(5):93-103

42. Karami J, Alikhani M, Zakiei A, Khodadadi K. The effectiveness of art therapy (painting) in reducing the aggressive behavior of students with dyslexia. J Learn Disabil. 2012;1(3):105-17.

43. Rabiee MR, Mahmodi KM. The effect of music on the rate of anxiety among hospitalized children. J Gorgan Univ Med Sci. 2007;9(3):59-64.

44. Whitehead-Pleaux AM, Baryza MJ, Sheridan RL. The effects of music therapy on pediatric patients' pain and anxiety during donor site dressing change. J Music Ther. 2006;43(2):136-53. https://doi.org/10.1093/jmt/43.2.136 PMid:16897906

45. Stratton VN, Zalanowski AH. The effects of music and paintings on mood. J Music Ther. 1989;26(1):30-41. https://doi. org/10.1093/jmt/26.1.30

46. Moammadi A, Raadin A. The effectiveness of art therapy on decreasing on depression, anxiety and aggression in preschoolers. J Anal Cogn Psycholoy. 2017;8(28):43-51.

47. Tahan YA, Moghpoo AJ. The effect of music therapy on stress, anxiety and depression in cancer patients. Indian J Palliat Care. 2018;7(3):186-93.

48. Jasemi M, Aazami S, Zabihi RE. The effects of music therapy on anxiety and depression of cancer patients. Indian J Palliat Care. 2016;22(4):455-8. https://doi.org/10.4103/0973-1075.191823 PMid:27803568 